\title{
Educação corporativa: análise dos sentidos do trabalho à luz da formação continuada
}

\author{
Karen Osório Arnt \\ Instituto Federal do Rio Grande do Sul (IFRS) \\ (karen.o.arnt@gmail.com) \\ Márcia Amaral Corrêa de Moraes \\ Docente. Instituto Federal do Rio Grande do Sul (IFRS) \\ (marcia.moraes@poa.ifrs.edu.br) \\ Josiane Carolina Soares Ramos do Amaral \\ Docente. Instituto Federal do Rio Grande do Sul (IFRS) \\ (josiane.amaral@poa.ifrs.edu.br)
}

\begin{abstract}
Resumo: O presente trabalho levanta algumas discussões sobre o sentido do trabalho na vida das pessoas e a importância da formação continuada no desenvolvimento pessoal e profissional do trabalhador. Com uma breve revisão bibliográfica em segmentos como educação, psicologia, administração e sociologia, o estudo tem o objetivo de apresentar concepções diversas, fazendo um contraponto entre alguns estudiosos do assunto. O significado de trabalho, desde os primórdios da sociedade em produção, é analisado e discutido, assim como questões são abordadas acerca do tema em estudos e pesquisas científicas: que espaço esse trabalho ocupa na vida dos indivíduos? O trabalho é uma fonte de realização pessoal? É um objetivo de vida ou somente uma função social? O trabalho pode ser alienante ou fetichizado? A busca pela formação continuada pode trazer prazer ou sofrimento para o indivíduo? Essas são indagações discutidas pelo presente estudo. A metodologia utilizada foi uma pesquisa qualitativa, utilizando como instrumento um questionário online, aplicado por meio da rede social Facebook, em um público diverso. Como complemento do estudo, foi realizada uma revisão bibliográfica acerca do tema. $\mathrm{Na}$ análise dos resultados foi constatada uma familiaridade entre as opiniões dos participantes com a mesma área de atuação profissional, porém a maioria dos respondentes expressam a mesma opinião quando referido o sentido do trabalho sob a ótica da qualificação humana e a constante busca pela realização pessoal e profissional.
\end{abstract}

Palavras-chave: sentido do trabalho; formação continuada; significação de trabalho.

\section{Corporate education: analysis of the senses of work in the light of continued training}

\begin{abstract}
This paper raises some discussions on the meaning of work in people's lives and the importance of continuing education in the personal and professional development of the worker. With a brief bibliographic review in segments such as education, psychology, administration and sociology, the study aims to present diverse conceptions, making a counterpoint among some scholars of the subject. The meaning of work, from the beginnings of the society in production, is analyzed and discussed, as well as questions are approached on the subject in studies and scientific research: What space does this work occupy in the life of individuals? Is work a source of personal fulfillment? Is it a life goal or just a social function? Can work be alienating or fetishized? Can the search for continuing education bring pleasure or suffering to the individual? These are inquiries discussed by the present study. The methodology used was a qualitative research, using as an instrument of online questionnaire, applied through the social network Facebook in a diverse public. As a complement to the study, a bibliographic review on the subject was carried out. In the analysis of the results, it was observed a familiarity among the opinions of the participants with the same area of professional activity, but most respondents express the same opinion when referring to the meaning of the work from the point of view of human qualification and the constant search for personal and professional.
\end{abstract}


Keywords: meaning of labor; continuing education; labor significance.

\section{INTRODUÇÃO}

O significado do trabalho na vida das pessoas é um tema explorado por alguns estudiosos de segmentos e opiniões divergentes, como Antunes (2008), Morin (2007), Borges (1997), Schwartz (1994), Tolfo e Piccinini (2007), refletindo sobre o sentido que o trabalho assume no desenvolvimento do profissional. $O$ presente artigo apresenta uma reflexão sobre o significado e o sentido do trabalho na vida dos indivíduos, buscando breves referenciais teóricos nas áreas de sociologia, psicologia e administração. Qual o sentido que o trabalho exerce nos indivíduos? A formação continuada gera prazer ou sofrimento em quem a realiza?

Buscando dados em um público bem diversificado, a metodologia utilizada nesse estudo foi uma pesquisa qualitativa, através de um questionário enviada de forma eletrônica, disponibilizado na rede social Facebook, em formato de enquete, com as duas questões principais: qual o sentido que o trabalho exerce na sua vida? Como você considera a formação continuada? As respostas foram de múltipla escolha.

O objetivo da pesquisa é contribuir para a compreensão do significado do trabalho na vida das pessoas, partindo da reflexão sob o ponto de vista dos valores atribuídos a este objeto de estudo e na eterna busca em dar sentido à vida das pessoas. Para Borges (1997, p. 16), estes atributos são os valores característicos do trabalho, com embasamento em Schwartz (1994), que define valor como "alvo transacional variando de importância" e servindo como guia na vida dos indivíduos.

Sob o ponto de vista dos trabalhadores e como objetivo estratégico das instituições, o que se almeja é um trabalho que permita com que o profissional coloque em prática suas habilidades e competências, que the traga um retorno financeiro para manter uma vida digna e proporcionar outras aquisições, incluindo lazer, e que o motive a buscar mais conhecimento visando um crescimento na sua carreira e o reconhecimento por isso.

A comprovação dessas hipóteses, por meio do instrumento de pesquisa aplicado online, distribuído na rede social Facebook, obteve 162 respostas. O perfil dos respondentes são trabalhadores: de instituições públicas (26\%), iniciativa privada $(47,5 \%)$, autônomos $(17,3 \%)$ ou outros $(9,3 \%)$. A grande maioria atua na 
área da educação (60,5\%). Para grande parte dos respondentes (63,6\%), o trabalho dá sentido à vida das pessoas, primeiramente como realização pessoal e profissional, seguido pela motivação para buscar mais conhecimento visando crescimento e o reconhecimento $(38,3 \%)$.

A formação continuada é considerada por 56,8\% dos respondentes como forma de aprender, conhecer e transformar seu trabalho e sua carreira, e a busca pelo crescimento profissional é tida como outro fator determinante da formação continuada por $48,8 \%$ dos entrevistados.

Com este propósito que a Educação Corporativa pode ser estudada como estratégia organizacional. De acordo com Brauer (2010), pelo dinamismo do mundo moderno e a rápida obsolescência das informações, a educação corporativa vem com a urgência da formação contínua do capital intelectual da empresa, através do desenvolvimento permanente dos seus colaboradores com base nos mais modernos conhecimentos.

\section{SIGNIFICADO DE TRABALHO}

Segundo Alves (2007), o processo de trabalho pré-capitalista ${ }^{1}$ era constituído por uma total autonomia dos homens livres e dos artesãos pré-capitalistas. $O$ processo de trabalho era determinado pelo trabalhador, pois estes eram detentores de um conjunto de habilidades técnico-pessoais adquiridas.

De acordo com Tolfo e Piccinini (2007), o trabalho é significado a partir da tarefa que cada indivíduo exerce e a consequência como representação social. A representação é social quando influencia diretamente na construção do grupo.

Quando o trabalho é identificado como resultado da tarefa executada, ele está sendo considerado individualmente para aquele sujeito, o reconhecimento externo ou a sua própria satisfação pessoal é o que constrói e fortalece essa identidade. Uma representação é para o grupo, em situações em que o trabalho é executado por uma classe social unida, em prol dos objetivos do grupo ou da organização. Há

1 "O processo de trabalho pré-capitalista constituía uma dimensão de autonomia dos homens livres e dos artesãos pré-capitalistas. O trabalhador artesão dominava o processo de trabalho e seus elementos, o meio de trabalho e seus objetos, além, é claro, de serem possuidores de um savoirfaire, um conjunto de habilidades técnico-pessoais adquiridas" (ALVES, 2007, p. 81). 
nestes casos, um forte sentimento de pertença. $O$ sentimento que o trabalho pode contribuir para algo maior, para o todo, para a sociedade é o que caracteriza o significado de trabalho como social.

Desde o início da reestruturação produtiva do capital vem ocorrendo uma redução do proletariado industrial, fabril, tradicional, manual, estável e especializado, herdeiro da era da indústria verticalizada de tipo taylorista e fordista. Antunes (2008) aborda o formato de proletariado vinculado aos ramos mais tradicionais vem cedendo lugar a diversas outras formas de trabalho, desregularizadas reduzindo fortemente a classe de trabalhadores estáveis que se estruturavam através de empregos formais, herança da fase taylorista/fordista.

\title{
3. MARX E O TRABALHO X CAPITAL
}

Antunes (2008, p.1) cita Marx (1871) ao definir o trabalho como parte fundamental na vida humana, reforçando que:

\begin{abstract}
$\mathrm{Na}$ longa história da atividade humana, em sua incessante luta pela sobrevivência, pela conquista da dignidade, humanidade e felicidade social, o mundo do trabalho tem sido vital. Sendo uma realização essencialmente humana, foi no trabalho que os indivíduos, homens e mulheres, distinguiram-se das formas de vida dos animais. É célebre a distinção, feita por Marx, entre o "pior arquiteto e a melhor abelha": o primeiro concebe previamente o trabalho que vai realizar, enquanto a abelha labora instintivamente.
\end{abstract}

O autor estabelece uma discussão quando diz que se por um lado, podemos considerar o trabalho como um momento fundante da vida humana, ponto de partida no processo de humanização, por outro lado, a sociedade capitalista o transformou em trabalho assalariado, alienado, fetichizado. O que era uma finalidade central do ser social converte-se em meio de subsistência. A força de trabalho torna-se uma mercadoria, ainda que especial, cuja finalidade é criar novas mercadorias e valorizar o capital. Converte-se em meio e não primeira necessidade de realização humana.

De modo semelhante, a especialização de funções, assim como a divisão do trabalho não teriam oportunidades de desenvolvimento se a lógica do mercado fosse somente a troca de produto por produto. Em consequência, o dinheiro foi introduzido 
como modo de facilitar as trocas e permitir operações de compra e venda, separadas em duas partes. (FRIEDMAN, 1962)

\section{SIGNIFICADO DO TRABALHO NA ATUALIDADE}

Segundo Tolfo e Piccinini (2007, p. 38):

O contexto do trabalho contemporâneo está articulado a uma série de alterações das mais diversas ordens. Essas mudanças incluem fenômenos tais quais a globalização dos mercados, o aumento da competitividade entre países ou empresas, a reestruturação produtiva, as inovações tecnológicas e/ou sócio-organizacionais, a flexibilização das relações de trabalho, dentre outras.

As autoras analisam os estudos sobre o sentido do trabalho de Hackman e Oldhan (1975) que identifica algumas variáveis na concepção do trabalho: a) o desenvolvimento de competências variadas para execução de tarefas diferentes com as quais há identificação do trabalhador; b) trabalho não-alienante, quando o profissional visualiza todo o processo de construção da sua tarefa e percebe a sua contribuição social, desenvolvendo autonomia, liberdade e responsabilidade; c) a importância do retorno sobre o seu desempenho é um fator determinante no conceito do trabalho.

Para Antunes (2008, p. 2), "[...] se a vida humana se resumisse exclusivamente ao trabalho, seria a efetivação de um esforço penoso, aprisionando o ser social em uma única de suas múltiplas dimensões", identificado assim como um trabalho que aliena, que não proporciona ao indivíduo a satisfação em fazer parte de algo, da construção social, da busca pela realização pessoal e profissional. E justamente este ser social tem necessidades de reconhecimento, de liberdade de decisão, de motivação para desenvolver-se e desempenhar bem o que the foi proposto.

Em contrapartida, Morin (1996) define o sentido do trabalho como uma estrutura afetiva formada por três componentes: o significado, a orientação e a coerência. O significado que as atividades desempenhadas representam na vida do sujeito, a orientação como a inclinação deste indivíduo para sua busca, seus objetivos e a coerência como o equilíbrio esperado da sua relação com o trabalho.

Para a classe trabalhadora hoje, é preciso reconhecer esse desenho compósito, heterogêneo e multifacetado que caracteriza a nova conformação da 
classe trabalhadora: além das clivagens entre os trabalhadores estáveis e precários, homens e mulheres, jovens e idosos, nacionais e imigrantes, brancos e negros, qualificados e desqualificados, "incluídos e excluídos", temos também as estratificações e fragmentações que se acentuam em função do processo crescente de internacionalização do capital. "Desse modo, um desafio maior da humanidade é dar sentido ao trabalho humano, tornando a nossa vida também dotada de sentido" (ANTUNES, 2008, p. 13).

\subsection{O sentido do trabalho como realização profissional}

Pesquisas que Morin (2001) realizou com estudantes de administração, administradores da França e do Quebec apontam cinco motivos para atribuírem sentido ao trabalho: para realizar-se e atualizar suas competências; para adquirir segurança e ser autônomo; para relacionar-se com os outros e estar vinculado a grupos; para contribuir com a sociedade; para ter um sentido na vida, o que inclui ter o que fazer e manter-se ocupado.

Estes estudos realizadas pelo grupo MOW (1987) e por Morin (1996, 2001) demonstram que a maioria das pessoas pesquisadas continuariam trabalhando, mesmo que se tivessem condições para viver sem o trabalho. Apontaram como determinante, para significar o trabalho nas suas vidas, o sentimento de pertença, o fato de ter uma meta ou objetivo na vida e o trabalho como ocupação (TOLFO e PICCININI, 2007).

\subsection{Aprendizagem como busca do significado para o trabalho}

As organizações, segundo Morgan (2000), são cérebros, pois lidam com um número infindável de dados e informações, que é compilado por sistemas informatizados e depois processado e analisado por pessoas que, por meio de inteligência, transformam informações em conhecimento.

Em uma época em que o talento se destaca é de fundamental importância, que as instituições possam suprir o público interno com conhecimento, desenvolvendo habilidades e competências, além de manter seus colaboradores motivados, trazendo de forma eficaz o retorno para a empresa, do que foi investido neste profissional. 
É imperativo contar com talentos humanos. A empresa deve estar atenta para transformar pessoas em talentos por uma multiplicidade de meios, atrelando organização do trabalho com uma cultura organizacional envolvente e participativa para engajá-los, além de criar um ambiente que privilegie o aprendizado e as oportunidades de realização do que se aprendeu.

Fochessato e Quadros (2012) relatam que as organizações têm desenvolvido suas estratégias de recursos humanos dentro da ideia da polivalência e multifuncionalidade, resultando em um corpo funcional qualificado, com múltiplas competências e considerado a alavanca estratégica para o sucesso da empresa.

Para Nonaka (1994), gerenciar o conhecimento é como ciclo de criação contínua do saber, "criação do conhecimento organizacional", organizações bemsucedidas são as que criam conhecimentos, disseminam-nos amplamente por toda a organização e, rapidamente, incorporam em novos produtos, serviços e tecnologias.

Antunes e Alves (2004) trazem a reflexão da necessidade crescente de qualificação e preparação para conseguir trabalho, incluindo a ideia de que grande parte dos trabalhadores utiliza do seu "tempo livre" para adquirir "empregabilidade 2 ".

De acordo com Marras (2011, p. 271), a empregabilidade pode ser medida como o nível de desenvolvimento ou atualização de um indivíduo frente às exigências do mercado, gerando mais competitividade e/ou oportunidade. A organização pode enxergar como vantagem acolher um profissional já qualificado, reduzindo gastos com desenvolvimento, porém a ideia de "garantir a formação de quadros com características que atendam às suas necessidades organizativas" pode ser mais benéfica para as instituições.

Para Éboli (2004), as empresas precisam de novas competências, com a consciência da necessidade de se objetivar e implantar sistemas eficazes garantindo e ampliando o desenvolvimento do capital humano com práticas pedagógicas desenvolvidas de forma planejada, sistêmica e alinhadas ao negócio.

Este é um formato de Educação Corporativa que Junqueira e Vianna (2003) definem como um "sistema de aprendizagem" focado no desenvolvimento de competências nos colaboradores da empresa. Para que isso aconteça de forma

2 Para Antunes (2004, p. 6), empregabilidade é "a palavra-fetiche que o capital usa para transferir aos trabalhadores às necessidades de sua qualificação, que anteriormente eram em grande parte realizadas pelo capital". 
mais eficaz, há de se motivar os sujeitos despertando o "desejo de aprender, de conhecer e de transformar seu trabalho e suas carreiras. Estas competências, sejam técnicas ou comportamentais, devem estar de acordo com as metas e objetivos estratégicos da instituição.

Davis e Newstrom (1989) reforçam que as forças motivacionais que são desenvolvidas, frutos do ambiente cultural em que estão inseridos, afetando na forma como significam o trabalho em sua vida. Para a Administração Estratégica de Recursos Humanos, segundo Marras (2011), é fundamental enfatizar o campo motivacional, instigando no colaborador a ideia de que uma tarefa, função, responsabilidade seja vista como um todo, valorizada pelo sujeito que a executa, reforçando nele suas forças motivacionais. Quanto mais o colaborador enxerga o seu trabalho recompensado, mais estará comprometido com a organização, e consequentemente com as metas por essa estabelecidas.

O autor considera de suma importância para a organização, a manutenção de programas de desenvolvimento de acordo com as necessidades reais da empresa, contemplando o colaborador ao satisfazer seus anseios psicológicos e a instituição. otimizando a qualificação do seu quadro dando continuidade à cultura organizacional.

Senge (2004) defende que a mudança ou a readequação organizacional parta da melhoria dos processos, por meio da aprendizagem individual e coletiva de seus colaboradores, de forma que as pessoas ganhem espaço para expandir continuamente a capacidade de criar os resultados. O que o coletivo aspira, acaba fortalecendo os seus membros e a aprendizagem construída em conjunto traz mais benefícios para todos.

Partindo do sentido social que o trabalho gera na vida das pessoas, momentos de ócio, de tempo livre são definidos como essenciais por Antunes (2005, p. 92):

Se o trabalho torna-se dotado de sentido, será também (e decisivamente) através da arte, da poesia, da pintura, da literatura, da música, do tempo livre, do ócio, que o ser social poderá humanizar-se e emancipar-se em seu sentido mais profundo.

Para cada pessoa o trabalho assume uma forma diferente, ocupa um lugar distinto na vida deste indivíduo. 


\section{METODOLOGIA}

O presente estudo buscou referências bibliográficas, procurando analisar o significado do trabalho sob óticas diversas.

Com o intuito, também, de investigar uma pequena amostra de profissionais, foi aplicado um questionário estruturado virtual por meio da rede social Facebook, sendo coletadas 162 respostas. Para traçar alguns perfis, foi solicitado que o respondente identificasse sua faixa etária, sexo, perfil da instituição em que trabalha, área de atuação e as questões específicas do sentido que o trabalho exerce na vida da pessoa e como considera a formação continuada. Com possibilidades de múltipla escolha, as duas últimas questões servirão para identificar algumas hipóteses.

\section{RESULTADOS}

Como resultados específicos obtidos com a pesquisa, identificamos o perfil dos respondentes, como pode ser observado nos gráficos 1, 2, 3 e 4:

1. Idade (162 respostas)

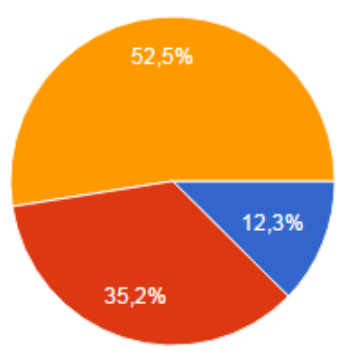

Gráfico 1: Idade

\section{Sexo (162 respostas)}

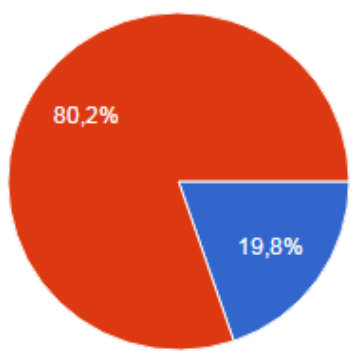


3. Você trabalha (162 respostas)

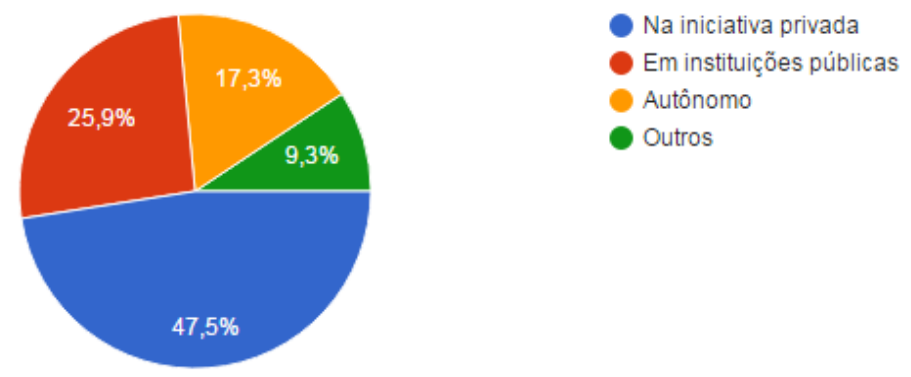

Gráfico 3: Local de trabalho

4. Qual sua área de atuação? (162 respostas)

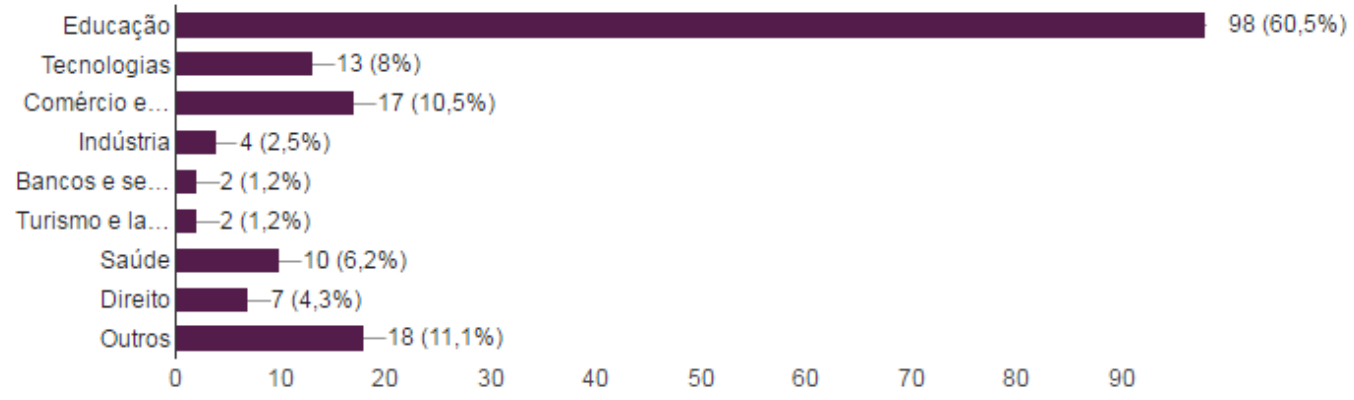

Gráfico 4: Área de atuação

A questão principal foi lançada com a intenção de discutir sobre o sentido que o trabalho exerce na vida dos indivíduos. As opções de respostas foram: "Realização pessoal e profissional"; "Motivação para buscar mais conhecimento visando crescimento e o reconhecimento"; "Estabelecer relações e estar vinculado a grupos"; "Contribuir para o ambiente social, com autonomia, liberdade e independência"; "Permite que você coloque em prática suas habilidades e competências"; "Adquirir segurança e ser autônomo"; "Conquista dignidade, humanidade e felicidade social". (Marx); "Somente uma fonte de sustento"; "Uma obrigação" e/ou "Gera alienação", como pode ser analisado no gráfico 5.

Para a maioria dos respondentes $(63,6 \%)$ a hipótese escolhida foi "Realização pessoal e profissional". Em seguida, 38,3\% dos participantes marcaram a "Motivação para buscar mais conhecimento visando crescimento e o reconhecimento", como forma de dar sentido ao trabalho. Também bastante considerada foi a hipótese "Permite que você coloque em prática suas habilidades e competências", como opção de 31,5\%. 


\section{Qual o sentido que o trabalho exerce na sua vida? (162 respostas)}

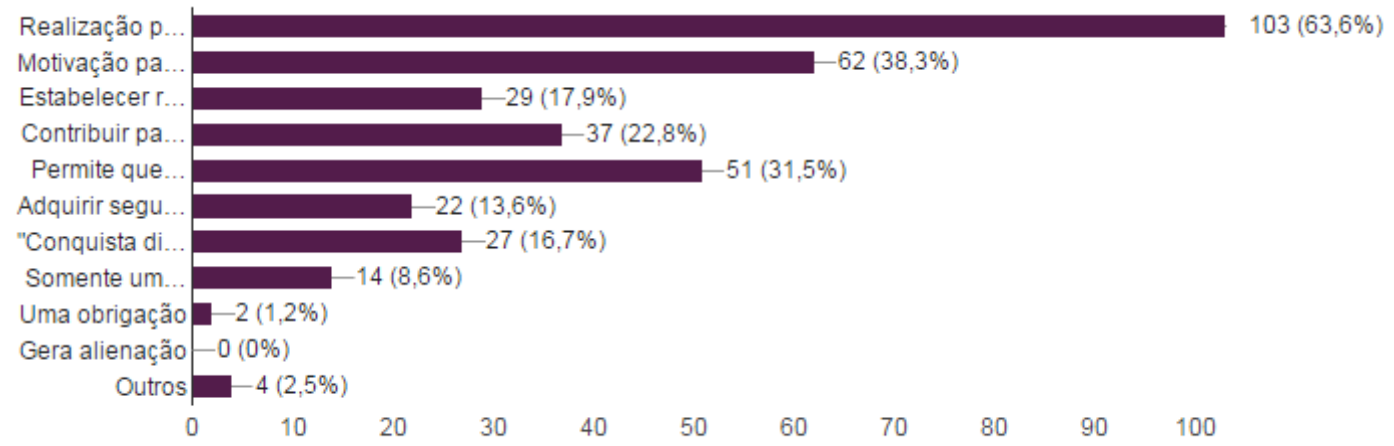

Gráfico 5: Sentido do trabalho

Analisando a informação perfil da instituição em que trabalha e comparando as esferas públicas ou privadas, mais especificamente "instituição pública", "iniciativa privada", "autônomo" ou "outros", com o sentido do trabalho, conclui-se que os funcionários públicos escolheram com mais ênfase o item "realização pessoal e profissional" (61,9\%), seguido da opção "motivação para buscar mais conhecimento visando crescimento e o reconhecimento" $(45,2 \%)$.

Uma hipótese com $33 \%$ de incidência foi "Permite que você coloque em prática suas habilidades e competências". Um único respondente considerou, na opção aberta, que "O trabalho contribui para a formação da minha autoimagem, e também supre a minha necessidade de realizar atividades desafiadoras, atingir objetivos, ou seja, de fazer algo no meu dia a dia".

$\mathrm{Na}$ iniciativa privada, os colaboradores têm uma visão um pouco diferente; como a insegurança é maior com relação à permanência no emprego, verifica-se que uma grande maioria escolheu "realização pessoal e profissional" $(74,02 \%)$ e o ponto de destaque é que esta opção é a única escolha em $51 \%$ dos que a escolheram. Este fenômeno não ocorreu nos funcionários públicos, que sempre citaram mais de uma hipótese.

Como segunda opção mais escolhida, assim como os funcionários públicos, vem a "motivação para buscar mais conhecimento visando crescimento e o reconhecimento" (40,26\%). Outra hipótese escolhida por um número considerável de respondentes da iniciativa privada é "Permite que você coloque em prática suas habilidades e competências" (26\%).

Borges (2001, p.13) trabalha com os conceitos do trabalho "rico de sentido individual e social" e cita os estudos de Fiske (1992) com relação à atribuição de 
significado, que é um processo subjetivo e individual, influenciado pelas intenções e habilidades cognitivas do sujeito.

A autora estudou acerca de certos padrões concebidos a partir de pesquisados, concluindo, entre outras questões, que "os padrões majoritários se caracterizam por atribuição de elevada centralidade ao trabalho e por articular valores econômicos (de sustento da vida) com expressivos (êxito e realização pessoal)" (BORGES, 2001, p. 11).

Outro aspecto explorado na pesquisa foi o papel da formação continuada na vida profissional do indivíduo, ilustrado no gráfico 6. Como opções de respostas foram propostas: "Realização pessoal"; "Crescimento profissional"; "Aprendizagem se constrói em conjunto"; "Forma de aprender, conhecer e transformar seu trabalho e sua carreira"; "Realizo somente por obrigação, se for exigido"; "É um sofrimento"; "Uma maneira de adquirir empregabilidade".

\section{Como você considera a formação continuada? (162 respostas)}

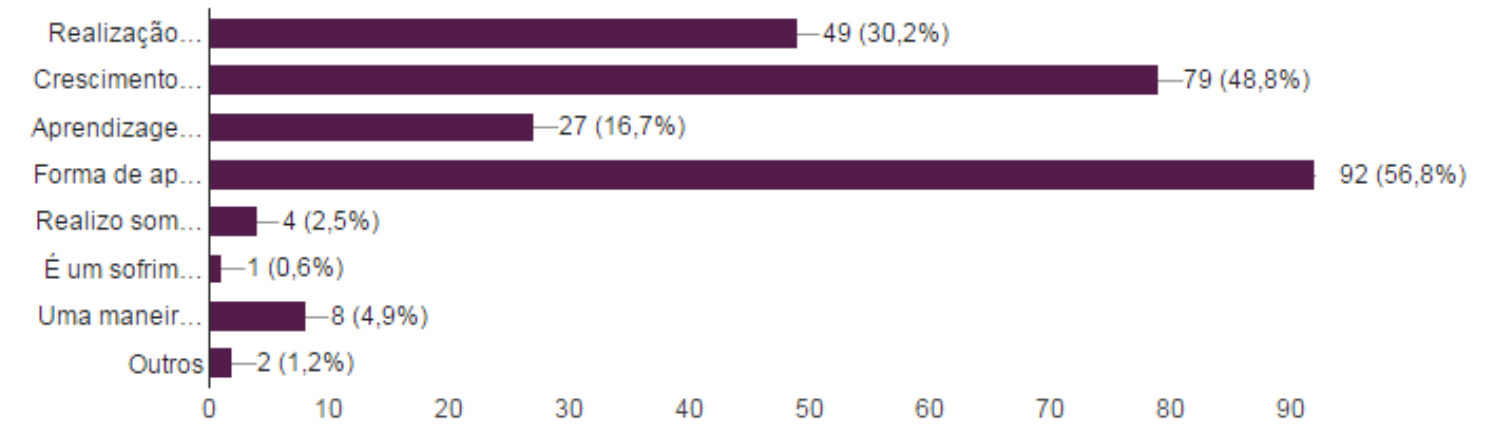

Gráfico 6: Formação continuada

Após análise, pode-se concluir que 56,8\% dos respondentes definiram como "Forma de aprender, conhecer e transformar seu trabalho e sua carreira"; a segunda opção mais escolhida foi "Crescimento profissional" (48,8\% dos respondentes). Se for verificar distintamente entre os grupos pré-selecionados de trabalhadores públicos ou de iniciativa privada, o resultado difere um pouco.

Pode-se observar que os $66,7 \%$ dos funcionários públicos consideram a formação continuada como "Forma de aprender, conhecer e transformar seu trabalho e sua carreira" e posteriormente o "Crescimento profissional" (50\%) e "Realização pessoal” (35,7\%).

A realidade dos profissionais da rede privada é invertida. Para 52\% dos respondentes, a formação continuada significa "Crescimento profissional", seguida 
da "Forma de aprender, conhecer e transformar seu trabalho e sua carreira" como alternativa com 48\% e "Realização pessoal", com 27,2\% das respostas.

Claro e Torres (2012) refletem sobre a capacidade de adaptação que as empresas devem ter frente às exigências de um mercado tão competitivo. $\mathrm{Na}$ iniciativa privada, os membros das empresas são constantemente motivados pela busca, reflexão e aplicação de conhecimentos nas tarefas diárias. Atrelado a isso, a percepção da dependência criada da empresa com relação ao seu maior patrimônio, o capital humano.

Borges (2001, p. 13) reforça o trabalho e seus significados como "categoria central da própria organização societal".

Antunes (2008) considera a transformação do trabalho humano a partir do advento do capitalismo, refletindo sobre os impactos causados, alterando e complexificando estes conceitos:

Essa dupla dimensão presente no processo de trabalho que, ao mesmo tempo cria e subordina, emancipa e aliena, humaniza e degrada, oferece autonomia, mas gera sujeição, libera e escraviza, impede que o estudo do trabalho humano seja unilateralizado ou mesmo tratado de modo binário e mesmo dual. (ANTUNES, 2008, p. 4).

A realidade entre estes dois públicos pesquisados, não levando em consideração pela baixa amostra de autônomos e outros segmentos, se torna similar quando refletimos sob a ótica da qualificação humana e a constante busca pela realização pessoal e também profissional. Os indivíduos como seres sociais, necessitam de integração e de reconhecimento pelo grupo no qual estão inseridos.

Não cabe a este estudo aprofundar estas questões, mas sim oferecer ao leitor um pequeno recorte sobre o significado do trabalho pesquisado por tantos estudiosos e refletido por inúmeros profissionais. Como o próprio Antunes, foco deste estudo, reforça em O trabalho e seus sentidos (2008), "uma vida cheia de sentido fora do trabalho supõe uma vida dotada de sentido dentro do trabalho".

Esta reflexão tende a ser diária por cada indivíduo, buscando sempre dar um sentido à sua vida, seja através do trabalho somente ou como soma de tantos outros fatores. Cabe levantar a hipótese, mesmo que com certa pretensão, de que o instrumento proposto pode ter levado a algumas reflexões por seus respondentes. 


\section{REFERÊNCIAS}

ALVES, Giovanni. Dimensões da Reestruturação Produtiva: Ensaios de Sociologia do Trabalho. Londrina, Editora Praxis, 2007.

ANTUNES, Ricardo. Século XXI: nova era da precarização estrutural do trabalho? Seminário Nacional de Saúde Mental e Trabalho. São Paulo, nov. 2008.

ANTUNES, Ricardo; ALVES, Giovanni. As Mutações no Mundo do Trabalho na Era da Mundialização do Capital. Educ. Soc., Campinas, vol. 25, n. 87, p. 335-351, maio/ago. 2004.

ANTUNES, Ricardo. O Caracol e sua Concha: ensaios sobre a nova morfologia do trabalho. São Paulo, Boitempo, 2005.

ANTUNES, Ricardo. O trabalho e seus sentidos: dimensões e crise estrutural do capital e suas respostas. Confluências - Revista Interdisciplinar de Sociologia e Direito, Programa de Pós-graduação em Sociologia e Direito, Universidade Federal Fluminense, vol. 10, n 1, p 43 a 61, Rio de Janeiro, 2008.

ANTUNES, Ricardo. Os Sentidos do Trabalho: ensaio sobre a afirmação e a negação do trabalho. São Paulo, Boitempo, 2009.

BORGES, L. O.; TAMAYO, A. A estrutura cognitiva e o significado do trabalho. Revista de Psicologia Organizações e Trabalho. 2011 vol: 1 (1989) pp: 2214-2224.

BORGES, L. O. Os atributos e a medida do significado do trabalho. Psicologia: Teoria e Pesquisa, 13 (2), 211-221, 1997.

ÉBOLI, M. Educação corporativa no Brasil: mitos e verdades. São Paulo, Gente, 2004.

FOCHESATTO, S. A.; QUADROS, M. S. P. Educação Corporativa. Curitiba: IESDE Brasil, 2012.

FRIEDMAN, Milton; Capitalismo e Liberdade. LTC, 1962.

JUNQUEIRA, L.A.C, VIANNA, M.A.F. Universidade Corporativa. Disponível em: <http://www.institutomvc.com.br/univcorp.htm>. Acessado em: 19 fev. 2003.

MARRAS, Jean Pierre. Administração de Recursos Humanos: do operacional ao estratégico. 14a. edição. São Paulo: Saraiva, 2011.

MARX, K. Os manuscritos econômicos e filosóficos: Vol. 22. Textos filosóficos. Lisboa, Portugal: Edições 70, 1993.

MORGAN, G. Imagens da organização: edição executiva. São Paulo, Atlas, 2000.

MORIN, E. M. Os sentidos do trabalho. Revista de Administração de Empresas, São Paulo, 41 (3), 8-19. 2001, jul./set.

MORIN, E.; TONELLI, M. J.; PLIOPAS, A. L. V. O trabalho e seus sentidos. In: Anais do XXVIII Encontro da Associação Nacional de Pós-Graduação e Pesquisa, 2003. 
MORIN, Estelle; TONELLI, Maria José; PLIOPAS, Ana Luisa Vieira. O Trabalho e Seus Sentidos. Psicologia \& Sociedade; 19, Edição Especial 1: 47-56, 2007

NONAKA, Ikujiro; TAKEUCHI, Hirotaka. Criação de conhecimento na empresa: como as empresas japonesas geram a dinâmica da inovação. Rio de Janeiro, Campus, 1997.

SENGE, P. M. A quinta disciplina: arte e prática da organização que aprende. São Paulo, Best Seller, 1998.

TOLFO, Suzana da Rosa; PICCININI, Valmíria. Sentidos e significados do trabalho: explorando conceitos, variáveis e estudos empíricos brasileiros. Revista Psicologia \& Sociedade. Vol.19. pp: 39-46, 2007. 